\title{
Impact of CoronaVirus (COVID19) in the Transport Management System: A Mini-Review
}

\author{
Majed Marzooq Alotaibi* \\ Technical and Vocational Training Corporation, Jeddah College of Technology, Jeddah, Saudi Arabia
}

\begin{abstract}
Human Coronavirus 2019 (COVID-19) is a consequence of severe acute coronavirus syndrome 2. The pandemic COVID-19 is an unprecedented, global pandemic. A novel COVID-19 affected human beings and a global public health emergency has been announced by COVID-19. In the global world, United States of America is the transport management system (TMS) is a global industry with a large market. TMS empowers to prepare, implement, and maximize the movement of goods, and to ensure that the transport is compliant, there are full and accurate records available at all times. Saudi Arabia is one of the leading TMS world widely. The aim of this review is to estimate the effect on transport management of the COVID-19 pandemic. The COVID-19 pandemic spread unpredictably around the world, infecting a number of nations with this epidemic. Nevertheless, globally and particularly in the United States was among the highly performed virus cases and mortality rates. Around the same time, even the transport/ traffic management system has affected this infectious disease. Saudi Arabia was also severely affected the impact of COVID-19 on TMS specifically the transport of international airports. The key goals for reinvigorating the growth potential in the future are to improve the production potential and increase employees. Future development of efficient distribution canals is expected to contribute to the potential growth of COVID-19 business TMS. This review concludes as COVID-19 has affected the TMS in the Saudi Arabia as well as global countries.
\end{abstract}

Keywords: Coronavirus, COVID-19, Transport management system and infectious disease

\section{Introduction}

Coronavirus becomes the major pathogens primarily targeting human respiratory system. ${ }^{1}$ Among the subtypes of CoVs; it has been found that COVID-19 is a terrible disease. ${ }^{2}$ On $30^{\text {th }}$ January has declared, COVID-19 as a health emergency throughout the world. ${ }^{3}$ Several recent reviews have since been published in literature describing various aspects of the global pandemic's effects, such as biological, economic, social and psychological. ${ }^{4}$ COVID-19 developed after 18 years of SARS in 2003 in China and 8 years after MERS virus in the Kingdom of Saudi Arabia. ${ }^{5}$ COVID-19 disease may be asymptomatic or cause symptoms that are mild, moderate, or extreme. Subsequent with this, a patient may require mechanical ventilation for developing an acute respiratory distress syndrome and some others may be allowed into the ICU. ${ }^{6}$ On 27 February 2020, KSA imposed restrictions on pilgrimages to the inbound Umrah, prohibited inbound travel by persons from the affected COVID-19 countries and restrictions on travel by Gulf Cooperation Council people trav eling to the affected COVID-19 countries for the first time during the eight decades of the Muslim pilgrimage to the Holy Sites of the kingdom of Saudi Arabia. By 7 June 2020, more than 0.1Million people have been infected with in the kingdom, while 283 deaths in most of the Saudi authorities in main cities, including Mecca, Riyadh, Jeddah and Medina, have been confirmed by the Saudi authorities. ${ }^{7}$ The virus spread rapidly in the Kingdom on 17 October 2020 , resulting in a total of 341,495 laboratory verified cases with 51,144 deaths. Social distancing and health facilities are advised for microbial contaminations with oxygen therapy, fluid management and use of antibiotics. The spread of COVID-19 could be managed early detection and management.8 In a large number of countries, before the COVID-19 crisis, tax revenue, the main type of public domestic capital and the largest source of development finance, were not adequate, especially in comparison with SDG spending requirements. Of the 124 countries eligible for Official Development Assis-

\begin{tabular}{l|l}
\hline Quick Response Code: & *Corresponding author: Majed Marzooq Alotaibi, Technical and Vocational Training Corpo- \\
ration, Jeddah College of Technology, Jeddah, Saudi Arabia \\
Received: 07 April, $2021 \quad$ Published: 04 Jun, 2021 \\
Citation: Majed Marzooq Alotaibi. Impact of CoronaVirus (COVID19) in the Transport Man- \\
agement System: A Mini-Review. Glob Scient Res Env Sci. 2021;1(4):1-4. DOI: \\
10.53902/GSRES.2021.01.000516
\end{tabular}


tance, with the tax revenue data published in 2017, more than one third had tax-to-GDP ratios of less than 15\%, a significant feature of successful government functioning and economic growth in this sample. At present, more than 12 trillion USD has been damaged by the COVID-19 pandemic across the world.

A study by Alkhamees et al., ${ }^{9}$ study describes the economic and psychological impact of COVID-19 on the overall Saudi Arabia population and findings indicate that $13.7 \%$ of those interviewed reported moderate or extreme psychological impact of outbreak and severe stress symptoms, which is analogous to $13.7 \%$. In comparison, $53.8 \%$ recorded moderate and extreme outbreak psychological effects, $16.5 \%$ and $28 \%$ reported moderate or serious outbreak symptoms of depression and anxiety, and $8.1 \%$ reported moderate to severe stress levels. ${ }^{10}$ The economic impact was drastically decreased throughout the global population and specifically in the Saudi population, TMS is one the source of economic. Lockdown and implementation of strict curfew halts the economy through TMS mainly by road transport, sea transport and air transport. Till date, the air transport is not full-fledged started within the KSA. Majorly, COVID-19 has affected the various modes of businesses world widely and in KSA due to the restrictions of curfew to control the spread of COVID-19 virus in the humans, business was severely affected.

\section{Transport System}

COVID-19 pandemic has a tremendous effect on transport systems as a major global solution to slow the spread of the disease is to limit movement of people. The consequence of the constraint of travel was that all the cities were riders. A number of public transit companies reduced their operation in reaction to the decline in ridership by retaining main routes and reducing all those from a weekday to a weekend schedule. For example, by closing 19 of 91 metro stations and decreasing frequencies to three or four trains per hour from ten trains per hour, the Washington Metropolitan Area transit authority reduced their services and it has also demanded, when using public transport, that all drivers cover their faces. In response to the government's new social separation law, public transit agencies have redesigned their operation and sought to preserve it. ${ }^{11}$ The providers of Mobility Services have published data based on location information, travel planner enquiries or application use. In several countries, e.g., Switzerland, Chile and Sweden, mobility trend surveys have been performed. While geographical conditions and data differ, a coherent trend indicates that private cars and other modes have suffered from particular harsh public transport. The decline in public transport is possibly due to limitations imposed by both the authorities and passengers. The limited physical space available for COVID-19 transmission, the number of surfaces that help to spread the virus and the limited testing of crews and passengers that use the device have been identified as high-risk conditions for public transit stations and cars. ${ }^{12}$

\section{Transportation Management System}

Definition of Transportation Management System (TMS) is a logistics platform that uses technology to support business ideas implementation and optimize physical movements. In large supply chain management system TMS plays a major role. ${ }^{13}$ The representation of TMS adopters is known to be diverse variety of businesses, with a known exceptional of high percentages of adopters using outsourced services to support decision-making. Adoption intentions tend to align with the strategic needs of the firm while functionality focuses on the day-to-day operational needs of the shipper. Although the device efficiency and return on investment exceptions differ considerably, TMS users are generally very happy. Non-adopters consider support for transport decisions to be of less significance. ${ }^{14}$ TMS is an integral part of the supply of chains, which influences all facets of the operation, from planning and acquisition to logistics and lifecycle management. The broad and profound visibility given by a powerful system allows transportation planning and implementation more effective. This contributes in fact to higher revenues and the growth of companies. It is important to build a framework that allows people to effectively navigate complex processes in terms of trade policy and regulation in a global trade world in which we live and trade. ${ }^{15}$ TMS is a system that simplifies the distribution process. It is a branch of the supply chain management of transport systems. A TMS enables shippers to simplify current processes and gain useful insights in order to save time and reduce potential shipment expenditure. The shipping method includes several movements both literally and figuratively - distribution firms, e-commerce organizations and everyone else who regularly moves freight. These freight shipments almost always search for ways to optimize investment and enhance procedures, from quotation to delivery.

\section{TMS Profits}

Technological capabilities: People have the technology to render routing choices dependent on quotations, travel times and carrier blends as shippers. A consolidated quote would reduce the unnecessary stress and time expended during the reservation process.

Simplify processes: A TMS will simplify the collection by helping people to determine the products that are delivered to a network provider and match them and can track past shipments and rapidly align comparable loads with the relevant companies by control of the whole operation in one location.

Cargo monitor: They can track cargo on the path through a TMS, and also get notifications from one stage for unexpected delays or exceptions to transit. However, as delays happen, and why a TMS is seen, it is difficult to monitor human error, or Mother Nature.

Competent insight: In-depth insights and reporting tools are generated by good transport management systems. For eg, let us assume that people track shipping processes at twenty locations where five shipments each are sent a week. That implies the production of 100 shipping invoices and the evaluation of shipments per week. All information is saved in a common place with a TMS, and personalized reports may be generated to examine variations in pricing and final invoices. 


\section{Types of TMS}

There are several forms of TMS to be found in regular shipment operations. We are depending on our business in the TMS. Enterprise, TMS facilitates the automating of the existing shipping method while at the same time extracting useful knowledge that save time and resources. Enterprise is suitable for big shippers that require personalized options, such as customer-specific pricing for committed account managers, and more.

\section{Difficulties in TMS}

Keeping organized citations: People don't want to stay on the phone or switch from website to website and query the network providers about prices while dealing with a variety of separate shippings. It will take time to dial various firms to order quotations, taking care of other facets of the market.

Choosing the best carrier: Not all exports are similar, Shipping is sometimes time or temperature sensitive, involves specialized shipping systems or must be done with strict caution. As a result, it is not appropriate to manage all shipments through one carrier. While certain operators can better handle long distances, others can deliver the specialist facilities and need at a low extra rate.

Shipping tracking: Not all the same carriers are used by all their cargo firms. A variety of shipments are usually transported across the map on different lorries. Thus, it can be very difficult to track freight. Without a TMS, anyone inside the business may have to input distribution numbers in form at a variety of separate courier facilities.

Collecting insights: Without a TMS, people may know who the cheapest carrier in the last year was, or who the best number of ontime shipments was. However, without the technology by the hand it's impossible to tell for certain.

\section{Intelligent Transport System}

Intelligent transport system (ITS) is known to mainly involve frameworks for the control of public transport, road traffic management and the application of traffic violations. Both vehicle surveillance and TMS fall under the ITS group. However, previous studies were addressing the ITS and vehicle monitoring systems. ${ }^{16}$ Including a range of communication, control, vehicle sensing and electronics technology, the ITS is an integrated system which helps track and manage traffic flows, reduces congestion, provides optimal routes for passengers, increases system reliability and saves lives, time and money. The World Bank Technical Note 'ITS for developing countries' explore the state of ITS in developing countries and investigate how ITS can bring long-term social advantages for individuals and how ITS can offer more immediate advantages by making surface transportation easier to reach, safer and efficient. ${ }^{17}$ It notes that ITS is helpful by

1. Increasing mobility of persons and freight, including increased access to transportation for the elderly, disabled people and people living in faraway areas.

2. Increasing communication between surface transportation and environment.
3. Reduced traffic-death and injury associated with transportation.

4. A more regulated transportation system.

5. Modern instability in the travel field, making travel more planned, quick and inferior.

6. From the above, we can see that almost all aspects of transportation engineering are covered by ITS and enhanced.

The most important and frequently used solution in transport and traffic issues worldwide is: Advanced Traveler Information System, Advanced Traffic Management System, Advanced Public Transit System and Emergency Management System. ${ }^{18}$ ITS enables various technological application in the TMS and is distinguished by the use of IT to collect, process and transfer traffic information to transportation users and operators. ${ }^{19}$ The vehicle surveillance system only takes into account vehicles i.e. auto-positioning systems, i.e. for example, vehicle surveillance and vehicle control as well as management can be expanded. Fix the problem of public transport commuters in Egypt wait to pillage in the middle of the road for long stretches, attempt to catch a bus with all their misery, the delay and the traffic that follows them. ${ }^{16}$

\section{Impact of COVID-19 in TMS and Segmental Research}

Digitalization of the transport industry is expected to fuel the growth over the next span of applications for transport management systems. The need for successful capture of real-time data could enhance TMS in the future. The segmental survey of the transport system management industry is conducted on the basis of product, distribution, industry and region. The transport device industry is divided into services, software and hardware depending on the components. On site and cloud, depending on deployment, the demand for the transport management system is split. In construction \& mining, travel \& tourism, health care, retail and others, the transport system market is segmented on the base of industry. Asia - Pacific, Middle East, North America, Europe, Africa and South America is divided into the transportation system market, based on regions.

\section{Conclusion}

The COVID-19 pandemic unexpectedly spread throughout the globe and this outbreak has infected a number of countries. The USA was, however, in the list of highly performed virus cases as well as death rates. At the same time the transport management system has also been affected with this infectious disease in the Saudi Arabia. The kingdom was mainly affected with financial crisis via TMS which is one of the sources of revenue. The economic and social impact has majorly affected by the COVID-19 in the humans. The focus on maximizing production capacity and upgrading workers is the top priorities to improve the market's growth potential in the future. The implementation of the COVID-19 market transport management system will be decided by creating efficient distribution channels.

\section{Acknowledgments}

None. 


\section{Funding}

None.

\section{Conflicts of Interest}

Author declares that there is no conflict of interest.

\section{References}

1. Thangavelu L. Role of Nanomedicine in Novel Corona Virus Pandemic: A Perspective. Biosc Biotech Res Comm. 2020;13(3):985-986.

2. Miraj SA. Coronavirus Disease 2019 The Public Health Challenge and Our Preparedness. Biosc Biotech Res Comm. 2020;13(2):361-364.

3. Sohrabi C, Alsafi Z, O'Neill N, et al. World Health Organization declares global emergency: A review of the 2019 novel coronavirus (COVID-19). International Journal of Surgery. 2020;76:71-76.

4. Al-Otaiby M. An Updated Literature Based Analysis on the Genetic Aspects of Coronavirus (COVID19) and its Connection with the Viral Genome. Biosc Biotech Res Comm. 2020;13(2):378-382.

5. Zhou F, Yu T, Du R, et al. Clinical course and risk factors for mortality of adult inpatients with COVID-19 in Wuhan, China: a retrospective cohort study. The lancet. 2020;395(10229):1054-1062.

6. Alzahrani SI, Aljamaan IA, Al-Fakih EA. Forecasting the spread of the COVID-19 pandemic in Saudi Arabia using ARIMA prediction model under current public health interventions. Journal of infection and public health. 2020;13(7):914-919.

7. Alyami MH, Naser AY, Orabi MA, et al. Epidemiology of COVID-19 in the Kingdom of Saudi Arabia: An Ecological Study. Frontiers in public health. 2020;8:1-9.

8. Yunus G. Corona Viral Disease-19 Outbreak: Research Publications, Trends and Their Visualization. Biosc Biotech Res Comm. 2020;13(3):987994.
9. Alkhamees AA, Alrashed SA, Alzunaydi AA, et al. The psychological impact of COVID-19 pandemic on the general population of Saudi Arabia. Comprehensive psychiatry. 2020;102:152192.

10. Wang C, Pan R, Wan X, et al. Immediate psychological responses and associated factors during the initial stage of the 2019 coronavirus disease (COVID-19) epidemic among the general population in China. International journal of environmental research and public health. 2020;17(5):1729.

11. Ahangari S, Chavis C, Jeihani M. Public Transit Ridership Analysis During The Covid-19 Pandemic. Med Rxiv. 2020;8:1-13

12. Jenelius E, Cebecauer M. Impacts of COVID-19 on public transport ridership in Sweden: Analysis of ticket validations, sales and passenger counts. Transportation Research Interdisciplinary Perspectives. 2020;8:100242.

13. Asari S, Kaneshiro T, Hosoda T. Transportation management system. Google Patents. 2005;9(6):1-18.

14. Griffis SE, Goldsby TJ. Transportation management systems: an exploration of progress and future prospects. Journal of Transportation Management. 2007;18(1):14.

15. McMullen GG, Hayden SR. Total transportation management system. Google Patents. 2007;7:1-12.

16. Ashour I, Zorkany M, Shiple M. Design and Implementation of Transportation Management System. In: VEHITS. 2015;9(7):11-18.

17. Yokota T. ITS for developing countries. Technical Note. 2004;22:1-14

18. Singh B, Gupta A. Recent trends in intelligent transportation systems: a review. Journal of Transport Literature. 2015;9(2):30-34.

19. Joseph AD, Beresford AR, Bacon J, et al. Intelligent transportation systems. IEEE Pervasive Computing. 2006;5(4):63-67. 